\title{
PENGARUH KEBISINGAN LALU LINTAS JALAN RAYA TERHADAP KONSENTRASI BELAJAR DI SEKOLAH
}

\author{
Rahma Dewi Ayu C \\ Jurusan Teknik Lingkungan, Fakultas Arsitektur Lanskap dan Teknologi Lingkungan, \\ Universitas Trisakti, Jakarta, Indonesia
}

Email korespondensi: rahma08214051@std.trisakti.ac.id

\begin{abstract}
ABSTRAK
Pesatnya perkembangan kota menyebabkan kebutuhan sarana transportasi meningkat. Meningkatnya volume kendaraan dan kecepatan kendaraan tentu menimbulkan dampak terhadap lingkungan sekitar berupa kebisingan lalulintas yang dapat memberikan dampak kebisingan pada kawasan pendidikan. Kebisingan merupakan bunyi yang tidak diinginkan dari suatu usaha atau kegiatan dalam tingkat dan waktu tertentu dapat menibulkan gangguan kesehatan pada manusia dan kenyamanan lingkungan, selain itu kebisingan dapat menimbulkan gangguan fisiologis dan psikologis pada manusia. Proses belajar mengajar akan berjalan dengan baik dan optimal apabila terhindar dari fator luar, salah satunya yaitu kebisingan. Berdasarkan KepMen LH No.48 Tahun 1996 tentang Baku Tingkat Kebisingan, untuk kawasan pendidikan tidak diperbolehkan melebihi $55 \mathrm{~dB}$. Karya ilmiah ini bertujuan untuk mengetahui pengaruh kebisingan lalulintas khususnya terhadap konsentrasi belajar siswa. Tingkat kebisingan diukur berdasarkan Keputusan Menteri Lingkungan Hidup Nomor 48 Tahun 1996 Tentang Baku Tingkat Kebisingan, yang dilakukan dengan mencatat data tiap 5 detik selama 10 menit di beberapa titik. Berdasarkan data yang telah diperoleh, $48 \%$ responden merasa konsentrasi terganggu saat kebisingan terjadi.
\end{abstract}

Kata Kunci: Kebisingan; dampak; pendidikan;

\section{PENDAHULUAN}

Peningkatan perekonomian di Indonesia menyebabkan kebutuhan sarana transportasi meningkat. Penggunaan jasa transportasi yang semakin meningkat, memberikan dampak terhadap lingkungan sekitar seperti, polusi udara,kemacetan dan kebisingan yang dapat mengganggu aktivitas manusia seperti mengganggu aktivitas seseorang dalam mengemban pendidikan.

Pendidikan merupakan kebutuhan dasar bagi manusia. Dalam proses kegiatan belajar mengajar tentu dibutuhkan kondisi lingkungan yang kondusif agar pembelajaran dapat berjalan dengan baik. Selain itu, dalam proses belajar mengajar tentu membutuhkan lokasi lingkungan fisik yang baik yaitu kondisi yang memberikan kenyamanan untuk para siswa belajar dengan optimal, sehat, aman dan selamat. Terhindar dari kebisingan merupakan salah satu penunjang untuk kondisi tersebut.

Kebisingan lalulintas yang tinggi pada rentang waktu yang cukup lama akan menimbulkan ketidaknyamanan dan membuat lingkungan sekitar menjadi terganggu. Apabila kebisingan melebihi baku mutu, dapat mengakibatkan penurunan pada kinerja belajar anak, terutama dalam belajar membaca yang membutuhkan konsentrasi. Selain itu, kebisingan dapat mengakibatkan gangguan lainnya terhadap civitas di sekolah seperti rasa kesal, ingin cepat marah, kuping berdengung, sakit kepala, dan menurunkan produktivitas kerja. Berdasarkan KepMen LH No. 48 Tahun 1996 tentang Baku Tingkat Kebisingan, peruntukan kawasan lingkungan sekolah tingkat kebisingan tidak diperbolehkan melebihi $55 \mathrm{~dB}$.

Karya Ilmiah ini bertujuan untuk mengetahui besar pengaruh kebisingan dari jalan raya khususnya terhadap konsentrasi siswa dalam proses belajar.

\section{TINJAUAN PUSTAKA}

\section{Kebisingan dan klasifikasinya}

Menurut Keputusan Menteri Lingkungan Hidup No.48 Tahun 1996, kebisingan yaitu bunyi yang tidak diinginkan dari suatu kegiatan atau usaha yang dalam tingkat dan waktu tertentu dapat menimbulkan gangguan kesehatan manusia dan kenyamanan lingkungan,

Berdasarkan Undang - Undang Nomor 22 Tahun 2009 tentang Lalu Lintas dan Angkutan Jalan, lalu lintas didefinisikan sebagai gerak kendaraan dan orang di ruang lalu lintas jalan, sedangkan ruang 
lalu lintas jalan adalah prasarana yang diperuntukkan bagi gerak pindah kendaraan, orang, dan/atau barang yang berupa jalan dan fasilitas pendukung.

Menurut World Health Organization (WHO), Kebisingan merupakan suara yang tidak diharapkan yang memiliki dampak berbahaya terhadap kesehatan manusia yang semakin penting untuk diperhatikan.

Davis dan Cornwell, (2013) mengklasifikasikan kebisingan menjadi kebisingan impulsif, kebisingan kontiyu dan kebisingan semikontinyu. Kebisingan impulsif merupakan kebisingan yang terjadi secara sepotong-sepotong dan tidak terus menerus, sedangkan kebisingan kontinyu merupakan kebisingan yang terjadi secara terus menerus dalam waktu yang cukup lama, dan kebisingan semi kontinyu merupakan kebisingan kontinyu yang terjadi hanya sekejap, kemudian hilang dan mungkin datang lagi.

Yadat (2014), mengatakan bahwa sumber bising dapat dibedakan menjadi 2 kategori, yaitu berdasarkan jenis dan sumber titik. Sumber bising dikelompokkan menjadi kebisingan kegiatan konstruksi, kebisingan industry, kebisingan kegiatan olahraga dan seni, dan kebisingan lalu lintas.

Klasifikasi kebisingan pada suatu kawasan atau lingkungan diatur dalam KepMenLH No.48 Tahun 1996 tentang Baku Tingkat Kebisingan yang dapat dilihat pada Tabel 1.

\section{Tabel 1. Baku Mutu Tingkat Kebisingan}

Sumber: KepMenLH No. 48 Tahun 1996, Tentang: Baku Tingkat Kebisingan.

\begin{tabular}{lr}
\hline Peruntukan Kawasan/Lingkungan & Tingkat Kebising \\
\hline a. Peruntukan Kawasan & \\
1. Perumahan dan Pemukiman & 70 \\
2. Perdagangan dan Jasa & 65 \\
3. Perkantoran dan Perdagangan & 50 \\
4. Ruang Terbuka Hijau & 70 \\
5. Industri & 60 \\
6. Pemerintahan dan Fasilitas & \\
7. Umum & \\
7. Rekreasi & \\
8. Khusus & 70 \\
- Bandar Udara *) & 60 \\
- Stasiun Kereta Api *) & \\
- Pelabuhan Laut & 55 \\
- Cagar Budaya & 55 \\
b. Lingkungan Kegiatan & 55 \\
1. Rumah Sakit atau sejenisnya & \\
2. Sekolah atau sejenisnya & \\
3. Tempat Ibadah atau sejenisnya &
\end{tabular}

\section{Keterangan :}

*) Disesuaikan dengan ketentuan

Menteri Perhubungan

\section{Dampak kebisingan dan pengendaliannya}

Menurut World Health Organization (WHO), kebisingan dapat menyebabkan gangguan pendengaran, mengganggu komunikasi, mengganggu tidur, menyebabkan efek kardiovaskular dan psiko-fisiologis, mengurangi kinerja, dan memicu respons gangguan dan perubahan perilaku sosial. Konsekuensi sosial utama dari gangguan pendengaran adalah ketidakmampuan untuk memahami pembicaraan dalam kondisi normal, yang dianggap sebagai hambatan sosial yang parah.

Kebisingan yang berlangsung dalam waktu yang cukup lama serta terus menerus pada manusia dapat mengakibatkan gangguan fisiologis seperti bergesernya ambang pendengaran dan dapat mempengaruhi kerja organ-organ tubuh. Selain itu, kebisingan juga dapat menimbulkan gangguan psikologis seperti sifat cepat marah, berkurangnya produktivitas kerja, dan sulit tidur, Wardika (2012).

Ernawati (2016) menyatakan bahwa kebisingan menimbulkan dampak terhadap kesehatan masyarakat seperti gangguan komunikasi dan gangguan psikologis seperti gangguan bekerja, gangguan belajar, gangguan tidur, kejengkelan, kecemasan dan lainnya.

Pengendalian bising dapat dilakukan secara alami dan buatan. Pengendalian secara alami dilakukan dengan pemasangan barrier, seperti menggunakan tanaman pucuk merah, tanjung dan ketapang. 
Sedangkan pengendalian secara buatan dilakukan dengan menghindari pintu dengan motif lekukan, memasang weather stripping pada tiap jendela, menggunakan cat peredam suara, dan menggunakan gorden yang terbuat dari tenunan tebal seperti brokat bermotif, beludru dan wol, Trixy (2018).

Ferial (2016) menyatakan bahwa upaya dalam pengelolaan kebisingan agar tidak masuk ke lingkungan dengan cara membangun penyekat kebisingan berupa penanaman pohon, meningkatkan kedisiplinan dalam berlalulintas, dan membatasi kendaraan yang parker di badan jalan.

\section{Kebisingan Kawasan Pendidikan}

Penelitian mengenai tingkat kebisingan lalu lintas terhadap sarana pendidikan telah banyak dilakukan, antara lain pengukuran kebisingan lalu lintas di SDN Jatinegara Kaum 03 Pagi dan 01 Pagi yang dapat dilihat pada Tabel 2.

Tabel 2.Rekapitulasi Tingkat Kebisingan Berdasarkan Hari Di Kedua Sekolah Dasar Sumber : Prasetyani (2018)

\begin{tabular}{ccc}
\hline Hari & Lseq SDN 03 dB(A) & Lseq SDN 01 dB(A) \\
\hline Senin & 77,1 & 76,5 \\
Selasa & 75,9 & 76,1 \\
Rabu & 77,1 & 77,3 \\
Kamis & 75,9 & 75,0 \\
Jum'at & $\mathbf{7 8 , 1}$ & $\mathbf{7 7 , 8}$ \\
Sabtu & 72,2 & 72,1 \\
Minggu & 69,5 & 67,2 \\
\hline
\end{tabular}

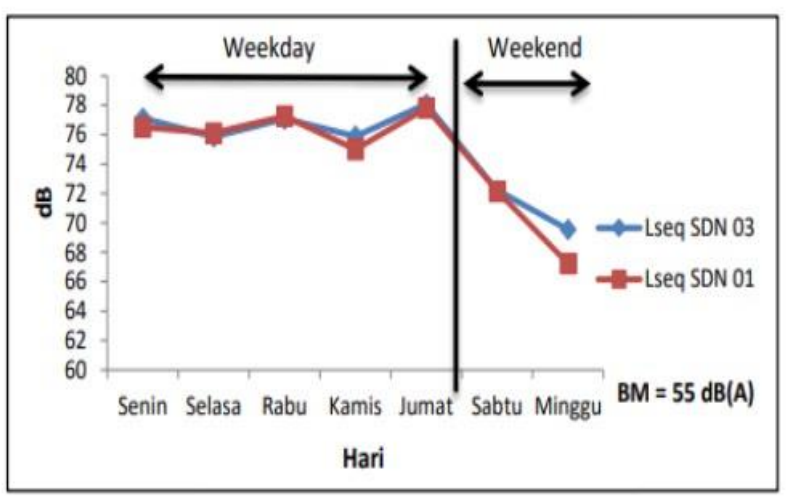

a)

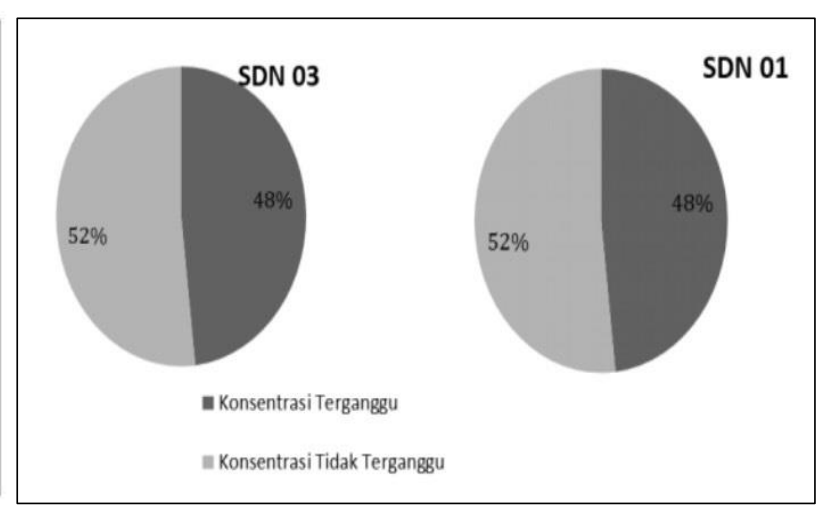

b)

Gambar 1. a) Grafik Rekapitulasi Tingkat Kebisingan Berdasarkan Hari di Kedua Sekolah

b) Diagram gangguan konsentrasi . (Sumber : Prasetyani ,2018)

Berdasarkan data diatas, tingkat kebisingan harian di SDN 03 dan SDN 01 Jatinegara Kaum, memiliki tingkat kebisingan tertinggi pada hari Jumat sebesar 78,1 dB(A) di SDN 03 dan 77,8 dB(A) di SDN 01. Nilai kebisingan di kedua sekolah tersebut sudah melewati baku mutu berdasarkan Baku Tingkat Kebisingan yang ditetapkan oleh KepmenLH No.48 Tahun 1996. Selain itu, sebanyak 48\% responden merasa kosentrasi terganggu saat kebisingan terjadi.

\section{METODE DAN ANALISIS DATA PENGUKURAN KEBISINGAN}

Berdasarkan Keputusan Menteri Lingkungan Hidup No.48 Tahun 1996, Pengukuran kebisingan dapat dilakukan dengan cara sederhana dan cara langsung. Cara sederhana dilakukan menggunakan Sound Level Meter yang diukur tingkat tekanan bunyi dB (A) selama 10 menit dalam tiap pengukuran serta dilakukan pembacaan tiap 5 detik, sedangkan cara langsung dilakukan dengan menggunakan Integrating Sound Level Meter yang mempunyai fasilitas pengukuran LTMS, yaitu Leq dengan waktu ukur setiap 5 detik, dilakukan pengukuran selama 10 menit.

Data perhitungan kebisingan yang didapatkan kemudian diolah menurut KepMen LH No.48/11/1996 menjadi 1 data tingkat kebisingan equivalen yang diukur tiap 5 detik selama 10 menit. 


$$
\begin{aligned}
& \text { Leq }(1 \text { menit })=10 \log 1 / 60\left(10^{0,1 . \mathrm{L} 1}+\ldots+10^{0,1 . \mathrm{L} 12}\right) .5 \mathrm{~dB}(\mathrm{~A}) \\
& \text { Leq }(10 \text { menit })=10 \log 1 / 10\left(10^{0,1 . \mathrm{L} 1}+\ldots+10^{0,1 . \mathrm{LX}}\right) .1 \mathrm{~dB}(\mathrm{~A}) \\
& \text { Leq }(\text { rata-rata })=10 \log 1 / \mathrm{n}\left(10^{\mathrm{L} 1 / 10}+10^{\mathrm{L} 2 / 10}+\ldots+10^{\ln / 10}\right) \\
& \mathrm{Ls}=10 \log 1 / 16\left(\mathrm{~T}_{1} \cdot 10^{0,1 . \mathrm{L} 1}+\ldots+\mathrm{T}_{4} 10^{0,1 . \mathrm{L} 4}\right) .5 \mathrm{~dB}(\mathrm{~A})
\end{aligned}
$$

Ln = Tingkat Kebisingan ke-n, $\mathrm{n}=$ Jumlah data, L1 = Tingkat Kebisingan ke-n,

Ls = Leq selama siang hari $\mathrm{dB}(\mathrm{A}), \mathrm{T} 1=$ Interval waktu (detik atau menit atau jam)

Leq $=$ Equivalent Continous Noise Level

\section{PENUTUP}

Dari uraian diatas, dapat dilihat bahwa tingkat kebisingan pada kedua sekolah sudah melewati batas baku mutu yang telah ditetapkan sebesar $55 \mathrm{~dB}(\mathrm{~A})$. Kebisingan yang ditimbulkan membuat $48 \%$ responden merasa konsentrasinya terganggu, sehingga menyebabkan proses belajar mengajar dan aktivitas di sekolah kurang berjalan dengan baik dan maksimal. Maka, perlu adanya perhatian khusus dan pengendalian yang dilakukan untuk mengurangi kebisingan tersebut.

\section{DAFTAR PUSTAKA}

Anggie Trixy, Hernani Yulinawati., Bambang Iswanto. 2018. Kajian Tingkat Kebisingan di Kawasan Pendidikan SD Negeri 06 Tanjung Duren, Jakarta Barat. Jakarta. Fakultas Arsitektur Lanskap dan Teknologi Lingkungan.

DOI: http://dx.doi.org/10.25105/psnkb.v1i1.2891

Arini Prasetyani, Bambang Iswanto, Hernani Yulinawati .2018. Kajian Tingkat Kebisingan Lingkungan pada Kawasan Pendidikan. Jakarta. Fakultas Arsitektur Lanskap dan Teknologi Lingkungan.

DOI: http://dx.doi.org/10.25105/psnkb.v1i1.2893

Davis, L. Mackenzie and Cornwell, A. David. 2013. Introduction to Environmental Engineering. United State of America: Mc Graw Hill.

Djalante, S. 2010. Analisis Tingkat Kebisingan Di Jalan Raya Yang Menggunakan Alat Pemberi Isyarat Lalulintas (APIL) (Studi Kasus: Simpang Ade Swalayan). Jurnal SMARTek. Vol. 8 No. 4. November 2010: 280-300.

Ernawati, Melati Ferianita Fachrul, Hernani Yulinawati. 2016. Analisis Pengaruh Tingkat Kebisingan Lalulintas Terhadap Lingkungan Kampus A - Universitas Trisakti A Grogol, Jakarta Barat dan Masyarakat di Sekitarnya. Indonesian Journal Of Urban and Enviromental Technology. DOI: http://dx.doi.org/10.25105/urbanenvirotech.v6i2.702

Kementerian Negara Lingkungan Hidup. 1996. Keputusan Menteri Negara Lingkungan Hidup Nomor Kep-48/MENLH/11/1996 tentang Baku Tingkat Kebisingan. Jakarta.

Linardita Ferial, Endro Suswantoro, Mawar DS Silalahi. 2016. Analisis Tingkat Kebisingan Di Terminal Pakupatan (Kabupaten Serang, Provinsi Banten). Indonesian Journal Of Urban and Enviromental Technology. DOI: http://dx.doi.org/10.25105/urbanenvirotech.v8i1.722

Presiden Republik Indonesia. 2009. Undang - Undang Nomor 22 Tahun 2009 Tentang Lalulintas dan Angkutan Jalan. Jakarta.

Wardika, dkk,. 2012. Analisis Kebisingan Lalu Lintas Pada Ruas Jalan Arteri. Universitas Udayana. Denpasar.

WHO. Occupational and community noise. Fact sheet no.258 Revised February 2001. (http://collections.infocollections.org/ukedu/en/d/Js0536e/)

Yadat T., (2014) Studi Power Level Kebisingan Kendaraan Ringan di Kota Makassar. Universitas Hasanuddin Makassar, Makassar. 
